\title{
Esophageal stent migration into the trachea
}

\author{
Massimo Conti, MD, Pasquale Ferraro, MD, Jocelyne Martin, MD, and \\ André Duranceau, MD, Montréal, Quebec, Canada
}

$\mathrm{T}$ he self-expandable esophageal prosthesis has helped the palliation of dysphagia in advanced esophageal cancer. However, the prevalence of complications and mortality are reported to be increased when chemo- and radiotherapy are added after the stent insertion. Radiation therapy is also a recognized etiologic factor in causing the appearance of a tracheoesophageal fistula (TEF), especially if the tumor is in close relation with the tracheobronchial bifurcation before being treated. This report aims at describing the development and progression of a wide tracheoesophageal fistula after the double insertion of a self-expandable prosthesis to treat a post-radiotherapy TEF. The approach to the problem is discussed with the results of treatment.

\section{Clinical Summary}

A 45-year-old man was admitted for progressive dysphagia for solids and liquids. A squamous cell carcinoma of the esophagus was documented between 28 and $35 \mathrm{~cm}$ of the incisors. The clinical staging suggested a T3 N0 M0 tumor. Curative radiotherapy was offered with 50 Gy of external beam irradiation given in 25 treatments. Endobrachytherapy was added with five 400-centiGray (cGy) treatments at $1 \mathrm{~cm}$ from the central axis. Four months after treatment, an esophagobronchial fistula was diagnosed. A self-expandable Gianturco stent (Cook-Canada Inc., Stouffville, Ontario, Canada) was installed. Eight months later, a recurrent tracheoesophageal fistula was documented above the first stent. A second self-expandable Wallstent prosthesis (Boston Scientific Corp, Boston, Mass) was positioned to cover the new fistula. Fifteen months after irradiation, intratracheal migration of the proximal flange of the Wallstent (Figure 1, A) resulted in midesophageal obstruction while threatening tracheal occlusion. The first consultation in surgery intervention occurred at this point, and the patient was referred to our unit.

Using a 5-mm bronchoscope to squeeze the anterior of the migrated stents, a guide wire and a small Savary bougie (Pilling Weck Canada Ltd., Markham, Ontario, Canada) were used to position two no. 5 endobronchial tubes in the distal left main bronchus first and then in the right main bronchus.

\footnotetext{
From the Department of Surgery, Université de Montréal, Division of Thoracic Surgery, Centre hospitalier de l'Université de Montréal, Montreal, Quebec, Canada.

Received for publication May 24, 2007; accepted for publication June 5, 2007.

Address for reprints: André Duranceau, MD, Department of Surgery, Université de Montréal, Division of Thoracic Surgery, Centre hospitalier de l'Université de Montréal, 1560 Sherbrooke E., Montreal, Quebec H2L 4M1, Canada (E-mail: andre.duranceau@umontreal.ca).

J Thorac Cardiovasc Surg 2007;134:1084-5

$0022-5223 / \$ 32.00$

Copyright $\odot 2007$ by The American Association for Thoracic Surgery doi:10.1016/j.jtcvs.2007.06.006
}

A right posterolateral thoracotomy was completed above the fifth rib. The entire serratus anterior muscle was dissected and protected. Esophagectomy was completed with removal of both stents, leaving the closed distal esophagus near the right crus. Complete destruction of the posterior wall of the distal trachea and of the origin of both main bronchi (Figure 1,B) became evident. The defect is $6 \mathrm{~cm}$ in length. The posterior trachea was repaired by using the mobilized serratus muscle to which a split-thickness skin graft was sutured to be used as an endobronchial lining (Figure 2, A). Separate resorbable monofilament sutures were positioned along the borders of the tracheobronchial defect and then passed through the cutaneous graft and the transposed muscle. The musculocutaneous patch provided a stable reconstruction of the tracheobronchial defect. A postoperative bronchoscopic scan revealed no paradoxical movement of the repair. The closed distal esophagus was left at the level of the right crus. A left parasternal esophagostome was created, and gastric drainage and subsequent feeding was ensured by an already present gastrostomy. The postoperative evolution was without complication, and the patient was discharged home after 14 days. On histologic analysis, there is no evidence of cancer in the resected esophagus. Reconstruction took place 4 months later. An uneventful total gastric interposition positioned substernally and anastomosed in the left neck afforded normal digestive continuity.

The patient was assessed every 6 months after the operation until his immigration to the United States. Two bronchoscopic evaluations took place, showing good healing of the skin graft on the transposed muscle and good stability of the musculocutaneous flap replacing the membranous tracheobronchial bifurcation (Figure $2, B)$. The patient lived comfortably for 8 years. He died of complications of cirrhosis and alcohol and drug abuse without any evidence of recurrent carcinoma.

\section{Discussion}

Ten percent to $20 \%$ of patients with esophageal carcinoma can have a fistula after irradiation. ${ }^{1}$ Whether these complications result from tumor progression or from the effects of radiotherapy on tissues, the biologic effects of irradiation favor the occurrence of damage. The self-expandable prosthesis used in this patient might have added pressure stress on irradiated tissues, causing further injury and, eventually, a large tracheoesophageal fistula., ${ }^{2,3}$

Today, a covered self-expanding esophageal stent still remains the most effective palliation to exclude the digestive tract from the tracheobronchial tree. ${ }^{4}$ If an unusually large tracheoesophageal fistula is present, surgical exclusion of the tracheobronchial tree from the alimentary tract might become necessary. Restoration of the alimentary continuity can then be deferred until the respiratory complications have been treated and a good nutritional balance has been obtained.

In this patient the use of a well-vascularized muscle flap covered by an epithelial lining, similar to the technique used by 

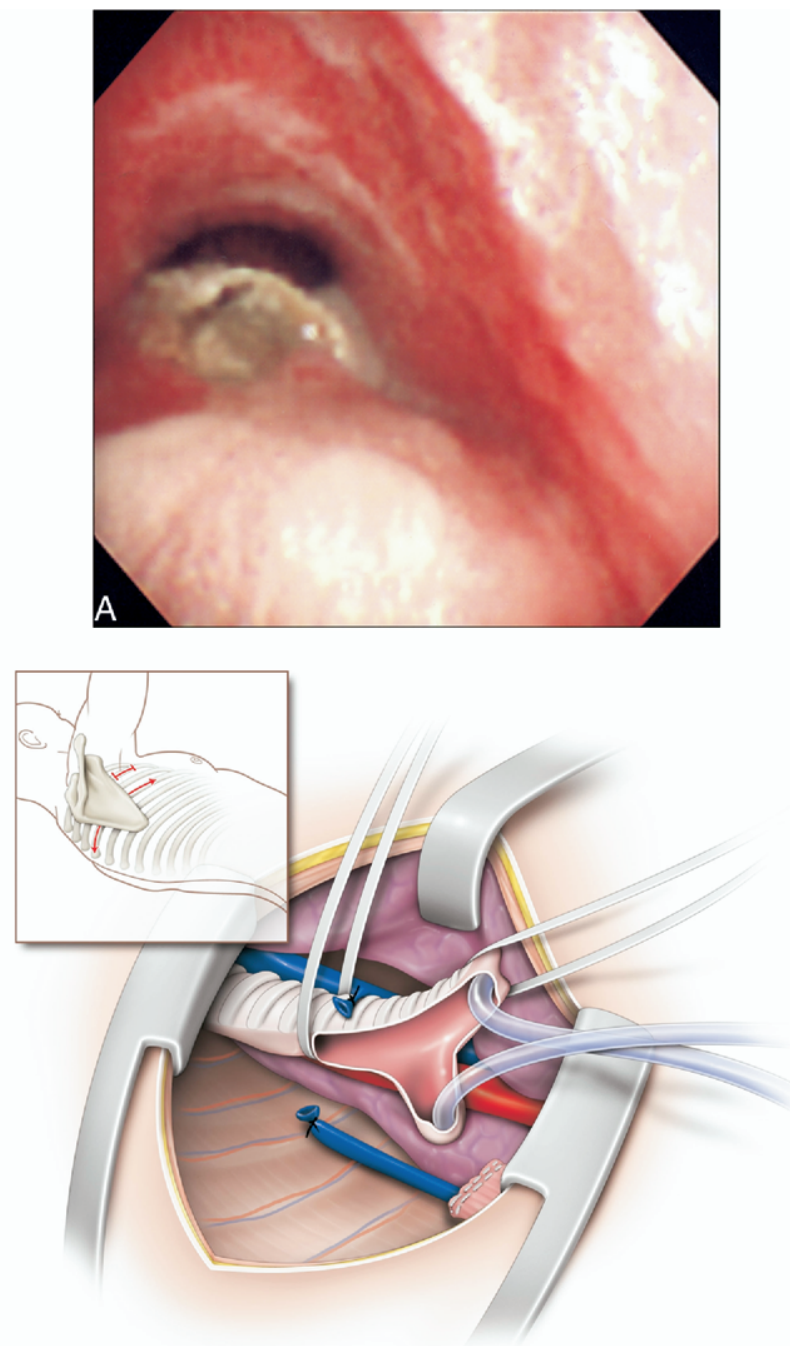

B

Figure 1. A, Bronchoscopic image: migration of the esophageal stent into the tracheal lumen. B, Tracheobronchial defect after esophagectomy and excision of the 2 stents. There is complete destruction of the posterior wall of the distal trachea, carina, and origin of the 2 main bronchi.

Hatafuku and Thal, ${ }^{5}$ provided primary healing, with a stable posterior muscular wall protecting the full integrity of the tracheobronchial lumen. Bronchial secretions were mobilized without difficulties. Restoration of the tracheobronchial tree and esophageal diversion gave ample time to control the persistent pulmonary infection, and the gastrostomy allowed for proper caloric intake.

Endoscopic positioning of a double intubation afforded safety, as well as stable cross-field ventilation, during the operation. Right lung exclusion made easier the completion of a difficult esophagectomy and allowed a better assessment of tracheal and main bronchi damage. The musculocutaneous repair healed well, providing comfortable ventilation to the patient for the remainder of his life.

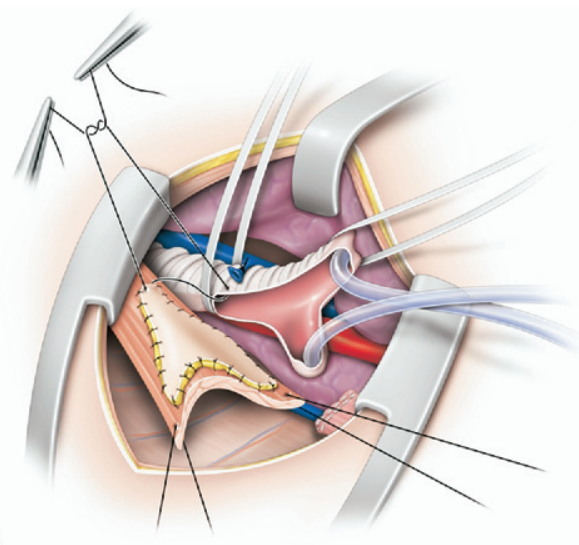

A

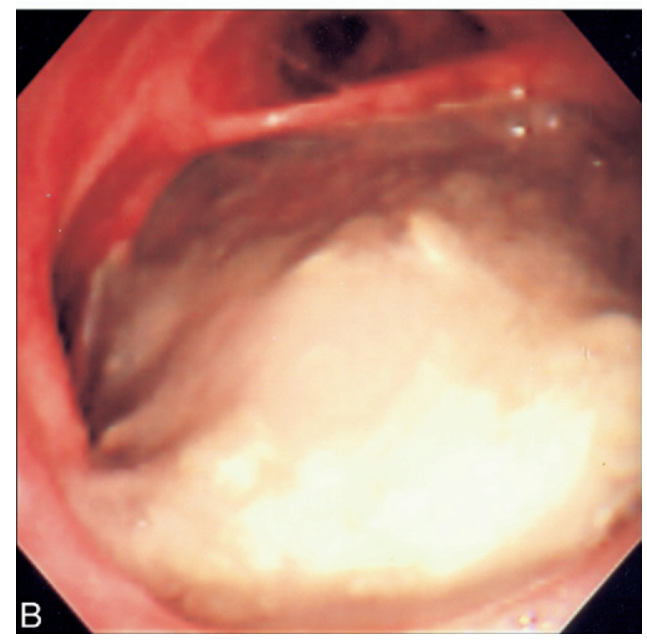

Figure 2. A, The muscle flap reaches the tracheobronchial bifurcation. The defect is measured, and the split-thickness skin graft is applied to provide the new endoluminal lining for the graft. Separate resorbable sutures are passed through the debrided tracheobronchial wall first and then through the musculocutaneous flap, providing an air-tight repair. B, Endoscopic view 2 years after the repair.

\section{References}

1. Rosenberg JC, Litcher AS, Leichman LP. Cancer of the esophagus. In: De Vita VT, Hellman S, Rosenberg SA, editors. Cancer: principles and practice of oncology. 3rd ed. Philadelphia: J.B. Lippincott; 1989p. 725-65.

2. Kinsman KJ, DeGregorio BT, Katon RM, et al. Prior radiation and chemotherapy increase the risk of life-threatening complications after insertion of metallic stents for esophagogastric malignancy. Gastrointest Endosc. 1996;43:196-203.

3. Siersema PD, Hop WC, Dees J, Tilanus HW, van Blankestein M. Coated self-expanding metal stents versus latex prosthesis for esophagogastric cancer with special reference to prior radiation and chemotherapy: a controlled, prospective study. Gastrointest Endosc. 1998;47: $112-20$.

4. Wu WC, Caton RM, Saxon RR, et al. Silicone-covered self expanding metallic stents for the palliation of malignant esophageal obstruction and esophagorespiratory fistulas: experience of 32 patients and review of the literature. Gastrointest Endosc. 1994;40:22-3.

5. Hatafuku T, Thal AP. The use of onlay gastric patch with experimental perforations of the distal esophagus. Surgery. 1964;56:556-60. 